\title{
Flora da Bahia: Theaceae
}

\section{Lucas Cardoso Marinho ${ }^{1 *}$, Wallace Messias Barbosa São-Mateus ${ }^{2, a}$, Grênivel Mota da Costa ${ }^{3, b}$ \& André Márcio Amorim 1,4,c}

${ }^{1}$ Programa de Pós-graduação em Botânica, Departamento de Ciências Biológicas, Universidade Estadual de Feira de Santana, Bahia, Brasil.

${ }^{2}$ Programa de Pós-graduação em Sistemática e Evolução, Universidade Federal do Rio Grande do Norte, Campus Universitário Lagoa Nova, Natal, Rio Grande do Norte, Brasil.

${ }^{3}$ Universidade Federal do Recôncavo da Bahia, CCAAB, Cruz das Almas, Bahia, Brasil.

${ }^{4}$ Departamento de Ciências Biológicas, Universidade Estadual de Santa Cruz, Ilhéus \& Centro de Pesquisas do Cacau, Herbário CEPEC, Itabuna, Bahia, Brasil.

Resumo - É apresentando o levantamento florístico de Theaceae para o estado da Bahia, Brasil. Apenas Laplacea fruticosa é registrada para o estado. São apresentados descrição, ilustração e comentários gerais para os táxons, além de mapa de distribuição geográfica da espécie na Bahia.

Palavras-chave adicionais: Ericales, Gordonia, Laplacea, taxonomia.

Abstract (Flora of Bahia: Theaceae) - A floristic survey of the Theaceae at Bahia state, Brazil, is presented. Only Laplacea fruticosa is recognized in the state. Description, illustration and general notes on the taxa, as well as geographical distribution map of species in Bahia are presented.

Additional key words: Ericales, Gordonia, Laplacea, taxonomy.

\section{THEACEAE}

Árvores ou arbustos perenifólios, ramos glabros a pubescentes. Folhas alternas, simples, sésseis a pecioladas, dísticas; lâminas oblanceoladas a elípticas, cartáceas a coriáceas, base cuneada a decorrente, margens inteiras, denticuladas e/ou serreadas, ápice agudo a obtuso, nervação cladódroma. Inflorescências terminais ou axilares, geralmente unifloras; bractéolas 2 ou muitas, caducas. Flores bissexuadas, actinomorfas; sépalas 4,5 ou muitas, livres ou unidas na base, imbricadas, geralmente persistentes; pétalas 5 ou muitas, livres ou fundidas, imbricadas; estames $5 \mathrm{ou}$ muitos, dispostos em ciclos, filetes livres ou unidos na base, anteras rimosas, dorsifixas; ovário súpero, 4-6(10)-carpelar, placentação apical-axilar ou axilar, 4 ou muitos óvulos por lóculo, estiletes livres ou unidos, estigma capitado ou lobado. Cápsulas com muitas sementes; embrião curvo.

Theaceae encontra-se posicionada na ordem Ericales. Análises filogenéticas utilizando marcadores plastidiais (Prince \& Parks 2001) demonstraram que Theaceae sensu Cronquist (1981) não é monofilética. Em sua circunscrição atual, a família está restrita à subfamília Theoideae (sensu Cronquist), com nove gêneros, aproximadamente 195 espécies e distribuição pantropical (Prince 2007). No Brasil, ocorre apenas o gênero Laplacea (Bitrtrich 2015).

\footnotetext{
*Autor para correspondência: lcmarinho1@gmail.com;

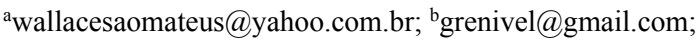

camorim.uesc@gmail.com

Editor responsável: Alessandro Rapini

Submetido: 31 jan. 2015; aceito: 8 abr. 2015

Publicação eletrônica: 28 abr. 2015; versão final: 6 maio 2015
}

\section{Laplacea Kunth}

Árvores ou arbustos. Folhas dispostas no ápice dos ramos, pecioladas, glabras ou não; lâmina coriácea a subcoriácea, geralmente assimétrica, margens serreadas, raramente inteiras, ápice agudo a arredondado, base atenuada, nervuras salientes na face adaxial. Inflorescências terminais. Flores com 5 ou muitas sépalas, desiguais, coriáceas, caducas, frequentemente seríceas na face abaxial; pétalas $5 \mathrm{ou}$ muitas, brancas, creme ou amarelas, desiguais, membranáceas, parcialmente seríceas na face abaxial, livres ou fundidas na base; estames numerosos, dispostos em 3 ou 5 ciclos, livres, filetes adnatos à base das pétalas; ovário globoso a oval, glabro ou seríceo, 4ou 5(-10)-locular, placentação apical-axilar ou axilar, 4(-6) óvulos por lóculo. Cápsulas loculicidas lenhosas; sementes aladas.

Laplacea possui distribuição pantropical, com três espécies nas Américas e cerca de 15 espécies no leste asiático (Bittrich \& Weitzman 2002; Prince 2007; Stevens 2015). No Brasil, Laplacea fruticosa é a única representante do gênero (Bittrich 2015).

A relação entre Laplacea e Gordonia J.Ellis é controversa e esses gêneros foram algumas vezes tratados como sinônimos (Sealy 1958; Keng 1980). Adotamos aqui a classificação de Prince \& Parks (2001), considerando Laplacea um gênero a parte, sendo este, também, o posicionamento adotado na lista da Flora do Brasil (Bittrich 2015).

1.1. Laplacea fruticosa (Schrad.) Kobuski, J. Arnold Arbor. 28(4): 437. 1947. Wikstroemia fruticosa Schrad., Gött. Gel. Anz. 1821: 711. 1821.

Figuras 1-3.

Árvores ou arbustos, 5-30 m alt.; ramos jovens pubescentes. Lâmina foliar $4-10 \times 1,2-4 \mathrm{~cm}$, elíptica 


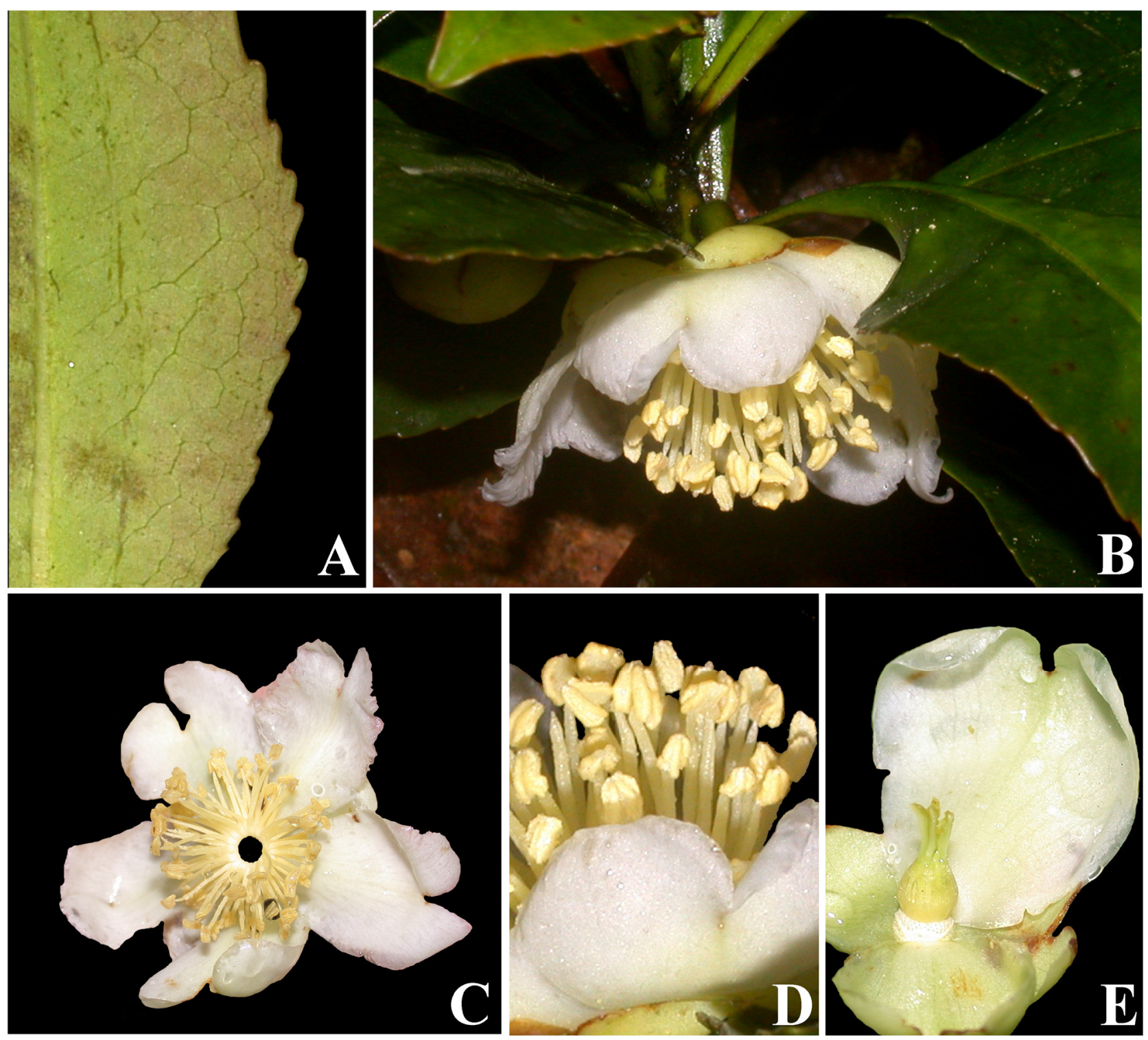

Figura 1. Laplacea fruticosa: A- detalhe da face abaxial da lâmina foliar mostrando a margem serreada; B- ramo com flor; C- pétalas e estames; D- detalhe da flor evidenciando os estames; E- detalhe da flor evidenciando o cálice, uma pétala e o gineceu (Amorim 6526; fotos: A.M. Amorim).

a oblanceolada, margens inteiras ou $1 / 3$ ou $2 / 3$ superiores serreados, glabras na face adaxial, levemente pubescentes na abaxial, assimétricas ou não; pecíolo 2-8 $\mathrm{mm}$ compr. Inflorescências unifloras; bractéolas 2, ca. $7 \mathrm{~mm}$ compr., suborbiculares. Botões florais verdes, seríceos. Flores com pedicelo 5-10 mm compr.; sépalas 5, 0,8-1,3 × 1,2-1,5 cm, cremeesverdeadas, suborbiculares, base truncada, ápice arredondado; pétalas 5, 1,7-2,5 × 1,2-1,9 cm, brancas a creme, livres, obovadas, base truncada, ápice arredondado, retuso a emarginado, face adaxial glabra, face abaxial serícea; estames ca. 100, amarelos a creme, dispostos em 5 ciclos, inseridos na base das pétalas, filetes 3-5 $\mathrm{mm}$ compr., anteras 1-2 $\mathrm{mm}$ compr.; ovário 3-5 mm compr., 5-locular, estiletes 5, 2,5-4 mm compr., glabros, estigmas sublobados. Cápsulas seríceas tornando-se glabrescentes na maturação, 1,8-2,5 × 1-1,5 cm, obovadas, 5-valvar, valvas bifurcadas.
Laplacea fruticosa é amplamente distribuída na América tropical, sendo encontrada desde Honduras até a Bolívia (Kobuski 1950; Woodson et al. 1967). No Brasil, ocorre da Amazônia à Região Sul (AccardoFilho 2004; Bittrich 2015). C7, D7, E6, F5, F6, $H 8$ e I8: campo rupestre e floresta ombrófila densa montana, em altitudes de 250 a $1750 \mathrm{~m}$. Coletada com botões a partir de agosto, flores de setembro a abril e frutos em junho.

Material selecionado - Abaíra, Gregória, $13^{\circ} 17^{\prime} \mathrm{S}, 41^{\circ} 54^{\prime} \mathrm{W}$, 15 dez. 1993 (fl.), W. Ganev et al. 2650 (CEPEC, HUEFS); Andaraí, 1248'S, 41²0'W, 17 set. 1984 (fl.), G. Hatschbach 48333 (CEPEC, HRB); Barra da Estiva, Morro do Ouro, 13²4'S, $41^{\circ} 18^{\prime}$ 'W, 16 nov. 1988 (fl.), R.M. Harley et al. 26464 (CEPEC); Camacan, RPPN Serra Bonita, 15²3'30'S, 39³3'55”W, 22 out. 2006 (fl.), A.M. Amorim et al. 6526 (CEPEC); Lençóis, 12²7’03”S 41'25'07'W, 9 jun. 1996 (fr.), M.T.S. Stradmann et al. 205

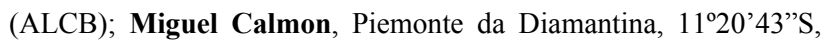
40³1'15"W, 31 ago. 2006 (bot.), T.F. Nogueira et al. 22 (ALCB); 


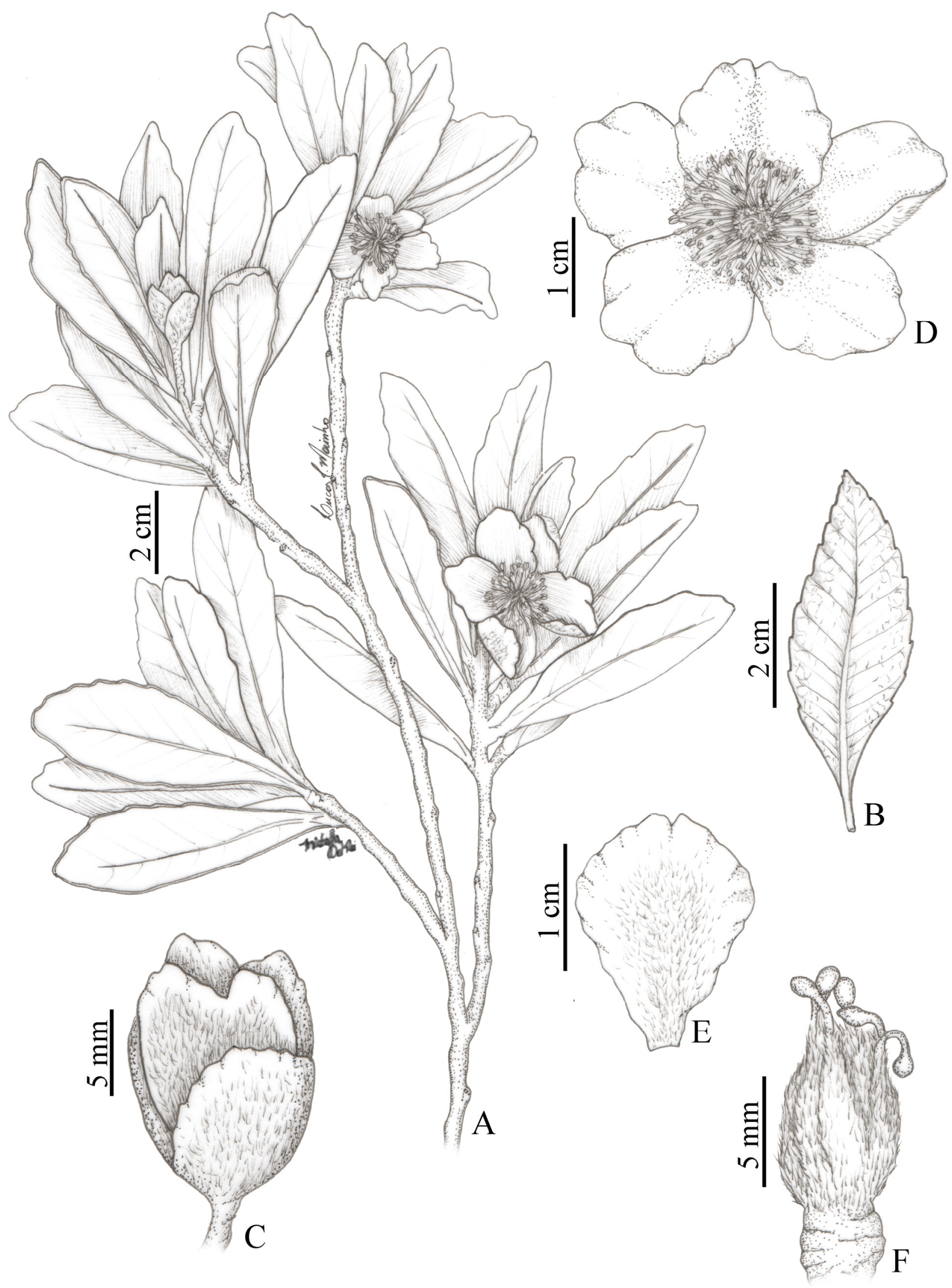

Figura 2. Laplacea fruticosa: A- ramo com flores; B- folha em vista abaxial (morfotipo simétrico); C- botão floral; D- flor; E- pétala, face abaxial; F- gineceu (A, C-F- Harley 27742; B- Amorim 6526; ilustrado por M. Teixeira e L. Marinho). 


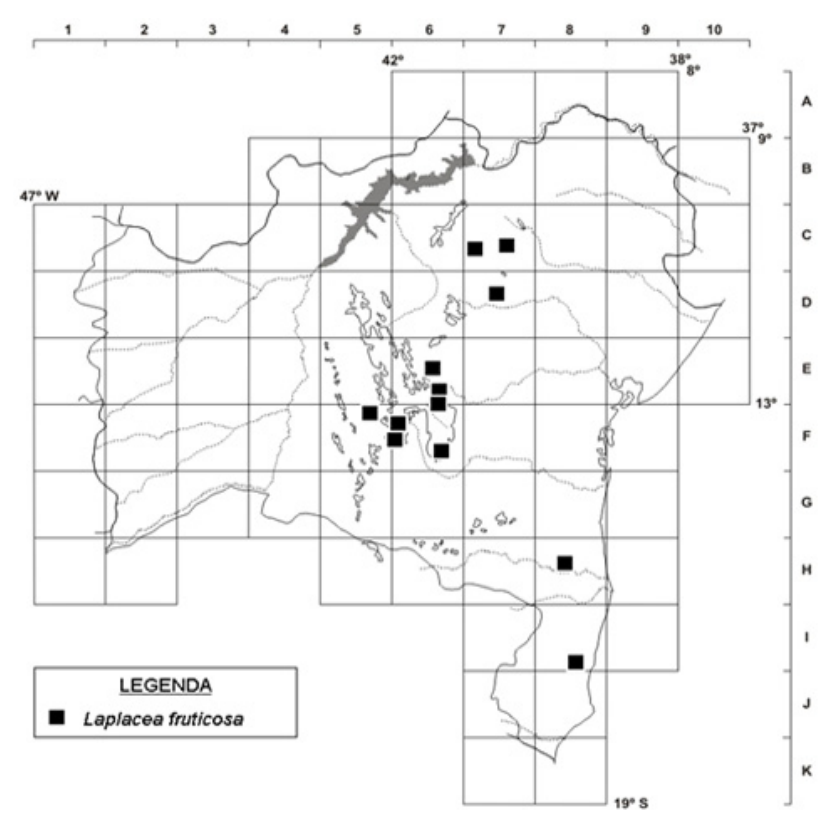

Figura 3. Distribuição geográfica de Laplacea fruticosa no estado da Bahia.

Mucugê, 1259'12”S, 41²0'39”W, 19 set. 1998 (bot.), M.L. Guedes et al. 6118 (ALCB, CEPEC); Pindobaçu, Serra da Fumaça, 10³9'S, 40²2’W, 26 out. 2008 (fl.), L.A. Sousa 160 (HUEFS); Porto Seguro, PARNA Monte Pascoal, 15¹5'53’'S, 40³4'29’'W, 14 nov. 1996 (fl.), W.W. Thomas et al. 11276 (CEPEC); Rio de Contas, Pico das Almas,

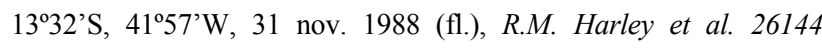
(CEPEC); Rio do Pires, Campo do Cigano, 1307'40”'S, 42¹7'31'W, 1 abr. 2000 (fl.), F.H.F Nascimento et al. 371 (ALCB, HUEFS).

Laplacea fruticosa é comumente confundida com espécies de Kielmeyera Mart. \& Zucc. (Calophyllaceae) pelo formato das flores, pétalas alvas, estames numerosos e pelos frutos do tipo cápsula, com sementes aladas. Pode ser imediatamente diferenciada de Kielmeyera pela ausência de látex e pelas lâminas foliares geralmente assimétricas, com margens serreadas do terço superior à base. Além disso, as inflorescências em Kielmeyera são terminais, em racemo ou panícula, a prefloração do cálice é quincuncial e o gineceu possui apenas um estilete (vs. inflorescências unifloras, cálice com prefloração não quincuncial e cinco estiletes) (Bittrich 2003).

Nos espécimes de Laplacea fruticosa da Bahia, o formato e a margem da lâmina foliar apresentam variação. Em alguns indivíduos, principalmente os provenientes das áreas de floresta ombrófila, as lâminas foliares são simétricas com margens serreadas em $2 / 3$ do comprimento, além de serem árvores que atingem cerca de $30 \mathrm{~m}$ de altura. Indivíduos com essas características foram tratados como Laplacea acutifolia (Wawra) Kobuski, considerado sinônimo de L. fruticosa por Bittrich (2015). Os espécimes encontrados em campo rupestre geralmente possuem lâminas foliares assimétricas com margens serreadas em $1 / 3$ do comprimento e, geralmente, possuem o hábito arbustivo, alcançando cerca de $8 \mathrm{~m}$ de altura. Esses caracteres, entretanto, não foram considerados suficientes para reconhecer L. acutifolia como espécie a parte. Além disso, indivíduos com lâminas foliares simétricas foram registrados também para áreas de campo rupestre.

\section{AgRAdecimentos}

Ao CNPq, pela bolsa concedida a LCM e pela bolsa de Produtividade em Pesquisa concedida a AMA (\# 306992/2012-4).

\section{REFERÊNCIAS}

Accardo-Filho, M.A.P. 2004. Theaceae no Estado do Rio de Janeiro. Dissertação de Mestrado. Museu Nacional/UFRJ, Rio de Janeiro.

Bittrich, V. 2003. Clusiaceae. In: M.G.L. Wanderley, G.J. Shepherd, A.M. Giulietti, M. Kirizawa \& T.S. Melhem (eds), Flora Fanerogâmica do Estado de São Paulo. Vol. 3. Fapesp e RiMa, São Paulo, p. 45-63.

Bittrich, V. 2015. Theaceae. In: Lista de Espécies da Flora do Brasil. Jardim Botânico do Rio de Janeiro. Disponível em http://reflora.jbrj.gov.br/jabot/floradobrasil/FB14923; acesso em 10 jan. 2015.

Bittrich, V. \& Weitzman, A.L. 2002. Theaceae. In: M.G.L. Wanderley, G.F. Shepherd, A.M. Giulietti \& T.S. Melhem (eds). Flora Fanerogâmica do Estado de São Paulo. Vol. 2. Ed. Hucitec, São Paulo, p. 323-326.

Cronquist, A. 1981. Theales. In: A. Cronquist (ed.), An Integrated System of Classification of Flowering Plants. Columbia University Press, New York, p. 301-340.

Keng, H. 1980. On the unification of Laplacea and Gordonia (Theaceae). Gardens' Bulletin (Singapore) 33: 303-311.

Kobuski, C.E. 1950. Studies in the Theaceae XX: notes on the South and Central American species of Laplacea. Journal of the Arnold Arboretum 31(4): 405-429.

Prince, L.M. 2007. A brief nomenclatural review of genera and tribes in Theaceae. Aliso 24: 105-121.

Prince, L.M. \& Parks, C.R. 2001. Phylogenetic relationships of Theaceae inferred from chloroplast DNA sequence data. American Journal of Botany 88(12): 2309-2320.

Sealy, J.R. 1958. A Revision of the Genus Camellia. The Royal Horticultural Society, London.

Stevens, P.F. 2015. Theaceae. In: Angiosperm Phylogeny Website. Version 12, July 2012 [and more or less continuously updated since]. Disponível em: http://www.mobot.org/MOBOT/ research/APweb/; acesso em 5 jan. 2015.

Woodson, R.E.; Schery, R.W. \& Rodyns, A. 1967. Flora of Panama. Part VI. Family 122. Theaceae. Annals of the Missouri Botanical Garden 54: 41-56. 


\section{LISTA DE EXSICATAS}

Amorim, A.M. 6526; Atkins, S. 4826; Conceição, A.S. 452; França, F. 1034; Ganev, W. 1500, 2616, 2619, 2649, 2650, 3169; Guedes, M.L. 6118, 6169, 20137; Harley, R.M. 26144, 26464, 27742, 30359, 50358, 53996; Hatschbach, G. 48333; Hurbath, F. 155; Nascimento, F.H.F. 194, 230, 254, 281, 371, 660; Nogueira, T.F. 21, 22; Oliveira, R.P. 81; Ribeiro-Filho, A.A. 92; Saar, E. 4826; Santana, F.A. 12; Santos, A.K.A. 156; Sousa, L.A. 160; Stradmann, M.T.S. 92, 205; Thomas, W.W. 11276 ; Vieira, T.L. 16, 21. 